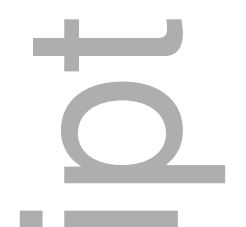

(

"It Felt Like Violence": Indigenous Knowledge Traditions and the

Postcolonial Ethics of Academic Inquiry and Community Engagement

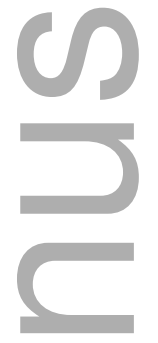

\author{
Joseph P. Gone, PhD \\ University of Michigan
}

Joseph P. Gone, Department of Psychology, University of Michigan.

I am grateful to Dr. Tiya Miles, Dr. Laurence Kirmayer, Dr. Rosalyn LaPier, and Dr. Symma Finn for their feedback in response to a draft of this article, and to the organizers and participants of the 2014 Meeting of the American Indigenous Research Association in Pablo, MT.

Correspondence concerning this article should be addressed to Joseph P. Gone, Department of Psychology, University of Michigan, 2239 East Hall, 530 Church Street, Ann Arbor, MI 48109-1043. E-mail: jgone@ umich.edu

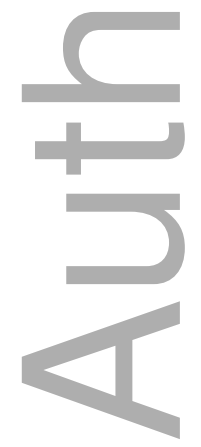

This is the author manuscript accepted for publication and has undergone full peer review but has not been through the copyediting, typesetting, pagination and proofreading process, which may lead to differences between this version and the Version of Record. Please cite this article as doi: $\underline{10.1002 / \text { ajcp. } 12183}$ 
Article Type: Original Article
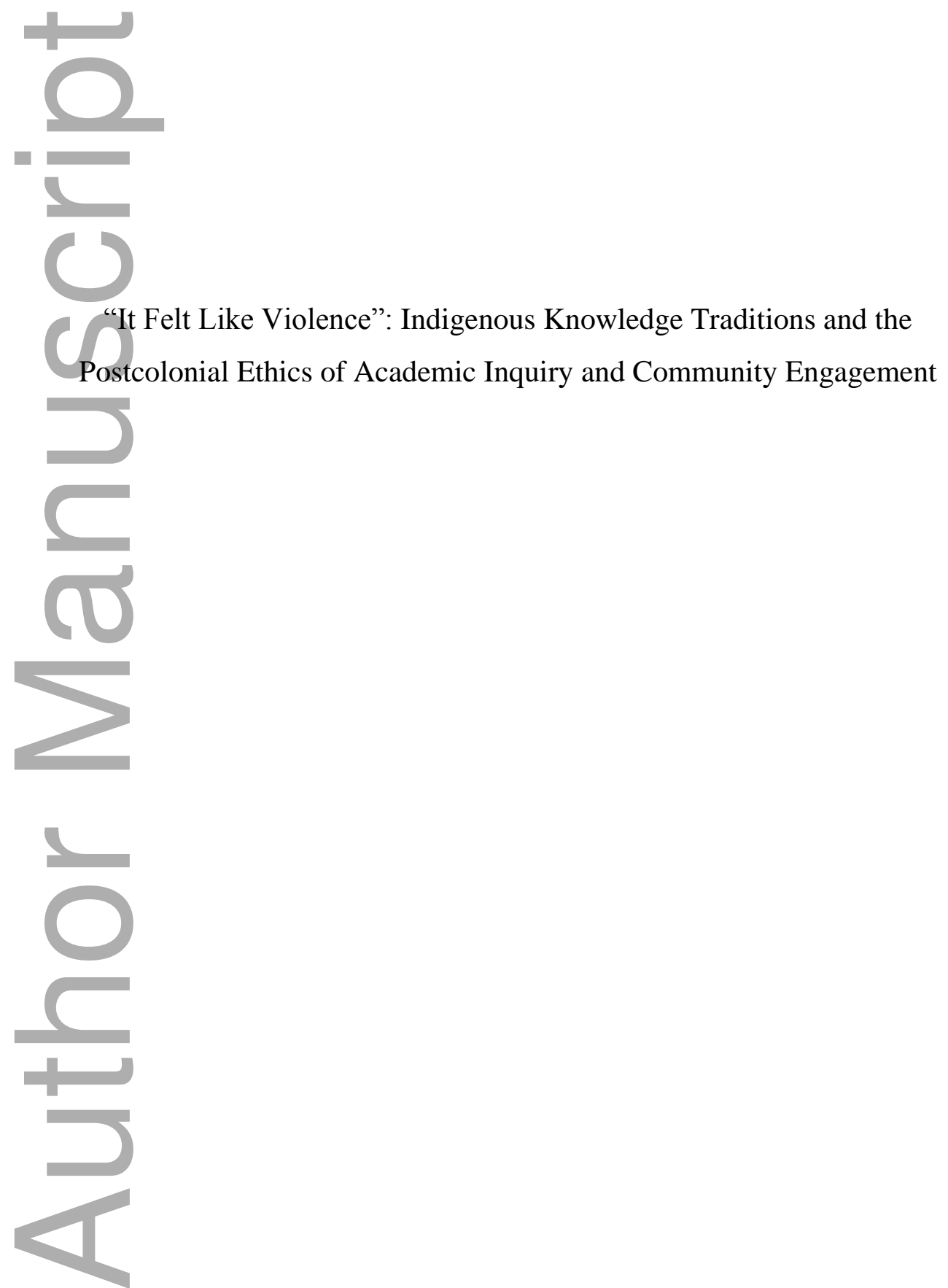


\begin{abstract}
In a 2014 presentation at an academic conference featuring an American Indian community audience, I critically engaged the assumptions and commitments of Indigenous Research Methodologies. These methodologies have been described as approaches and procedures for conducting research that stem from long-subjugated Indigenous epistemologies (or "ways of knowing”). In my presentation, I described a Crow Indian religious tradition known as a skull medicine as an example of an indigenous way of knowing, referring to a historical photograph of a skull medicine bundle depicted on an accompanying slide. This occasioned consternation among many in attendance, some of whom later asserted that it was unethical for me to have presented this information because of Indigenous cultural proscriptions against publicizing sacred knowledge and photographing sacred objects. This ethical challenge depends on enduring religious sensibilities in northern Plains Indian communities, as embedded within a postcolonial political critique concerning the accession of sacred objects by Euro-American collectors during the early twentieth century. I complicate these ethical claims by considering competing goods that are valued by community psychologists, ultimately acknowledging that the associated ethical challenge resists resolution in terms that would be acceptable to diverse constituencies.
\end{abstract}

Keywords: American Indians, indigenous knowledge, alternative methodologies, community psychology, ethical challenges

"It Felt Like Violence": Indigenous Knowledge Traditions and the Postcolonial Ethics of Academic Inquiry and Community Engagement Campbell (2016) has characterized community work as "sticky" with respect to navigations by community psychologists of "the complexities of interconnected people, organizations, and agendas, facing demands that often leave us feeling wary and unsure." Beyond a designation for interconnectedness, the term "sticky" also captures the possibility for getting "stuck." For this special issue dedicated to ethical challenges in community psychology, I present and reflect on an incident from my own recent experience that was "sticky" in this sense. In reviewing this ethical predicament, I trace competing values that structure this dilemma, and conclude that it resists resolution in terms that would be acceptable to diverse constituencies.

\title{
Framing the Ethical Challenge
}


As a university-based cultural-clinical-community psychologist, I have dedicated my career to advancing psychosocial well-being in American Indian communities. This commitment has led me to identify local concepts of wellness and distress within Indigenous community settings (Gone, 2007), to uncover the principles and logics of Indigenous therapeutic traditions relative to professional psychosocial interventions (Gone, 2010), to consider the relevance of Indigenous ways of knowing for evaluating intervention outcomes (Gone, 2016), and to reimagine the clinical enterprise from the perspectives of Indigenous community members (Gone \& Calf Looking, 2015). I do so as a member of the Gros Ventre tribal community of the Fort Belknap Indian reservation in Montana. Thus, my investment is both professional and personal.

These scholarly contributions routinely draw on Indigenous knowledge traditions (IKTs), including tacitly understood and distinctively expressed facets of Indigenous selfhood and interaction as well as explicitly elaborated and intentionally conveyed aspects of sacred understanding and ceremonial practice. Such IKTs are Indigenous in the sense that they are maintained and expressed by contemporary American Indian people who trace their ancestry (and, often, some proportion of their lifeways) to the aboriginal inhabitants of North America. Such IKTs are epistemic in the sense that they afford understanding, inference, insight, reasoning, and rationale for people in routine life circumstances. Such IKTs are traditional in the sense that they exhibit clear (though not impermeable, untouched, or "pristine") continuity with past aboriginal ways of existence. IKTs are plural in the sense that they encompass a variety of epistemic practices that were and are in use by Indigenous North Americans.

One additional feature of IKTs is impossible to overemphasize: these epistemic practices were deliberately denigrated, suppressed, and (in some cases) eradicated during the long colonization of North America by European settlers. Whether as casualties of dramatic population decline or coercive cultural assimilation, the postcolonial survival of these IKTsand, indeed, of American Indian cultural traditions more generally - is as remarkable as it was improbable. Thus, it should come as no surprise that American Indian communities today retain a vibrant stake in cultivating and protecting these endangered traditions. One expression of this commitment has been the articulation and promotion of "Indigenous epistemologies" - and their attending "Indigenous Research Methodologies" — by faculty and students at colleges and universities dedicated to advancing Indigenous Studies. 
The ethical challenge that I review in this article arose following a presentation I offered at a conference dedicated to the celebration and promotion of Indigenous Research Methodologies (IRMs) at a Montana tribal college in 2014. Briefly, IRMs are designated approaches and procedures for conducting research that are said to reflect long-subjugated Indigenous epistemologies (or "ways of knowing"). A common claim within this nascent movement is that IRMs express logics that are distinctive from academic knowledge production in "Western" university settings, but that these can result in innovative contributions to knowledge if they are appreciated in their own right and on their own terms. In my invited remarks, I elected to enter a critical voice within ongoing conversations about these matters that are still taking shape within Indigenous Studies circles. In so doing, I was careful to frame my entire presentation as addressed to the context of formal academic knowledge production.

\section{Describing the Ethical Challenge}

I deliberately sought to offer a critical perspective on IRMs in my conference presentation, primarily because the enthusiasm on behalf of these knowledge practices within Indigenous Studies has so far eclipsed a nuanced examination of constituent assumptions and consequential claims. And yet, to have engaged this topic at all reveals my interest in recognizing, appraising, appreciating, understanding, and reproducing IKTs. In fact, my concern is that community-based IKTs may (paradoxically) become more vulnerable to distortion, displacement, and even disappearance as a consequence of the uncritical promotion of academically-grounded IRMs. Thus, I sought to raise general questions, offer respectful critiques, and stimulate further progress in our collective project of identifying and preserving IKTs, especially in relationship to academic knowledge production.

To this end, I structured my presentation in four parts. First, I reviewed Ten Postulates of IRMs to make explicit my understanding of the basic assumptions and common commitments shared by proponents of IRMs (e.g., that differentiable Indigenous epistemologies persist in tribal communities today, or that IRMs prescribe distinctive ways of conducting inquiry that will yield novel insights and answers to pressing questions). Second, I offered three sets of Key Questions that proponents of IRMs will need to address in substantive fashion (i.e., what is an Indigenous epistemology?, who is an Indigenous knower?, and how should we actually make use of Indigenous epistemologies for purposes of academic knowledge production?). Third, I shared Eight Misgivings I harbor about IRMs, at least as they have been commonly described (e.g., 
IRMs appear to be culturally essentialist, insulate proponents from skeptical interrogation, obscure our debts to "Western" intellectual traditions, and resituate research as identity expression more so than as knowledge contribution). Finally, I offered three Take-Away Ideas about IRMs (i.e., that IKTs are not well-suited for academic knowledge production, that IKTs will require substantial alteration to become useful for academic inquiry, and that IRMs are best described as mixed, hybrid, or Métis forms of inquiry).

These remarks were quite controversial, fueled in part by an overcrowded conference schedule that reserved no time for audience exchange. A controversial conference presentation in and of itself raises no ethical challenges, of course; rather, the ethical dilemma of interest here arose from one facet of this presentation. Specifically, in setting up the Key Questions section of my address, Ihoped to provide a vivid and concrete example of an Indigenous "way of knowing" that might anchor the many abstract ideas that were to follow. I selected for this purpose a Crow (Absaroka) Indian medicine bundle known as the Braided Tail skull medicine (Wildschut, 1960). A medicine bundle is a collection of sacred objects and ritual materials that are wrapped together in hide or cloth until ceremonially opened for purposes of accessing sacred power. This bundle was obtained from Crow tribal members (along with some 260 other medicine bundles) by an amateur ethnologist and museum collector named William Wildschut during the years 19181927. Wildschut transferred these objects to the Museum of the American Indian in New York City (now part of the Smithsonian Institution) and prepared a monograph (published posthumously) on Crow Indian medicine bundles based on his consultations with knowledgeable community members during those years (Mason, 1961).

My PowerPoint slide accompanying this example included Figure 36 from Wildschut's monograph, a black-and-white photograph of the bundle's contents that displays the skull of the deceased eighteenth-century Crow medicine man named Braided Tail. In practice, the bundle was opened and the skull ceremonially consulted in oracle-like fashion by tribal members who desired pressing information, such as the proximity of an enemy war party or the location of a missing person or object. Its last ceremonial keeper, the wife of Old Alligator, consulted the skull medicine about a serious illness during her final days. She ritually inquired as to the benefit of visiting yet another doctor, and the skull medicine confirmed that doing so could not save her life. She thus avoided the expense of further medical opinion, and died soon thereafter. Here, I proposed, was an early prototype of an IRM - albeit one mostly unfamiliar to modern audiences, 
including American Indians - that could assist us in thinking through these complex issues. And yet, as I advanced to the photo of the Braided Tail skull medicine, I heard an audible reaction from those in attendance. I provisionally interpreted this as nervous laughter, perhaps in response to the unfamiliar, but others later recalled a collective gasp from the audience, most likely an expression of shocked sensibilities.

I proceeded. The talk concluded. The conference carried forward. But almost immediately following this presentation, other American Indian conference participants began to convey their discomfort with my discussion of the Braided Tail skull medicine. In fact, a group of students who took offense at my remarks seemed particularly outraged by my display of the photograph, suggesting later that my exhibit had crossed an ethical line. One student asserted: "[The photograph] offended me deeply. I too had a very visceral reaction and felt like crying. It felt like violence." But why should display of a dated photograph from an obscure anthropological monograph have occasioned such extreme emotional reactions and vehement ethical objections in the context of an otherwise substantive discussion of IKTs?

\section{Elucidating the Ethical Challenge}

A fair appraisal of this ethical challenge requires further elucidation of at least two related ethical claims. The first ethical claim is that academic presentation of the Braided Tail skull medicine violates longstanding religious convictions in many tribal communities surrounding the publicizing — and especially the photographing — of sacred objects, including medicine bundles. The underlying logic for this proscription is that such representations are disrespectful to the sacred "objects" in question. Here the English language term object falls short in reference to sacred bundles such as the skull medicine because not only are such materials considered by tribal traditionalists to be alive (or animate), but in practice they are related to as persons. That is, medicine bundles, when ritually opened by knowledgeable individuals in accordance with strict ritual protocols, are understood to exhibit several features of personhood such as agency, intentionality, compassion, communication, etc. Moreover, these other-than-human persons (Hallowell, 1976) are typically much more powerful than humans, able to undertake suprahuman tasks in response to sincere human requests. It is precisely this function that led northern Plains peoples to pursue power through medicine bundles for a variety of purposes (e.g., success in war, raiding, doctoring, gambling, seduction). In many instances, such power was obtained by an individual who, in response to personal prayer and sacrifice, was gifted by other-than-humans 
with the requisite ritual knowledge to construct a medicine bundle. Access to power through the bundle depended on ritual protocols retained solely by its "owner," although medicine bundles (and attending knowledge) could be transferred from one individual to another.

The disrespect associated with publicizing — and especially photographing — sacred objects such as medicine bundles is associated with adverse consequences. First, the ritual knowledge associated with these bundles was typically private, protected in secret by the owners. The sharing of such knowledge beyond the relationship between the bundle and its owner was an interpersonal affront that might lead an other-than-human benefactor to abandon the owner and to cease exercising power on his or her behalf. Second, and more important, the sacred power exercised by these other-than-humans was understood as potentially dangerous to humans, particularly when deployed against someone by a rival or enemy (as in cursing), but also as a consequence of offending (or disrespecting) such beings through deliberate insult or even inadvertent ritual mistakes. It was this latter concern for giving accidental offense in ceremonial practice that underscores the longstanding emphasis in northern Plains tribal communities on performing ritual protocols with exacting correctness during sacred traditional activities. The contemporary reality, of course, is that much of this procedural knowledge is lost, a casualty of the colonial encounter. Such loss has fueled anxiety and apprehension about the persistence and survival of Indigenous ritual activities - and the dangers of attempting to revitalize these practices in the absence of proficient ceremonial expertise-for generations of tribal members throughout the reservation era. In sum, the sacred power associated with medicine bundles explains both the continuing significance of these among northern Plains peoples as well as the heightened sensitivities surrounding their contemporary use and public acknowledgment.

The second ethical claim that explains audience objections to academic presentation of the skull medicine follows from this loss of traditional knowledge about sacred objects such as medicine bundles. Framed as anticolonial resistance and postcolonial critique, this claim depends on an assertion of contaminated knowledge that is, in turn, predicated on specific interpretations of the circumstances of accession of sacred objects (and attending knowledge) by EuroAmerican outsiders from tribal communities. With respect to the 260 Crow medicine bundles secured by Wildschut during the third decade of the twentieth century, this critical interpretation can be summarized in the account that follows. During a truly desperate time for the Crow people, an amateur collector (or "culture vulture") appeared in their midst to secure any of their 
remaining ceremonial relics. Oiling his way from clan to clan while resorting to unscrupulous chicanery (e.g., grave robbery, as suggested by one student from the audience), Wildschut assembled this collection to hawk these relics to a famous museum back east for a handsome profit. Thus, these medicine bundles - which formerly occupied such a prominent role in Crow sacred tradition until suppressed by White missionaries and government officials-were obtained by illegitimate means. It follows that their entry into the annals of anthropological knowledge via Wildschut's (1960) monograph was ethically tainted, and should now be stricken from the scholarly record due to the tawdry and exploitative circumstances of their accession.

Thus, the ethical challenge surrounding academic consideration of the Braided Tail skull medicine emerges from a body of shared traditional religious understandings that proscribes the publicization - including photography — of sacred objects such as medicine bundles, nested within a broader postcolonial critique that emphasizes the unscrupulous accession of such materials by Euro-American outsiders in the context of "salvage anthropology" (I will refer to this critique as the Culture Vulture account). These ethical claims are not suited for breezy adjudication by standing professional or research ethics guidelines insofar as they express long subjugated religious sensibilities, reflect postcolonial community perspectives, and challenge the tenets of academic knowledge production. Resolution of this ethical predicament must consider competing goods that may be difficult to reconcile for diverse constituencies.

\section{Complicating the Ethical Challenge}

The ethical challenge elucidated here depends on community religious sensibilities, embedded within a broader postcolonial political critique. Prior to substantive engagement of these, I wish to convey my appreciation for both lines of reasoning in the context of modern American Indian thought and experience. I also propose, however, that the Braided Tail skull medicine reveals competing benefits that emerge at the confluence of academic inquiry and community engagement. Indeed, it is precisely these tensions or trade-offs that render this ethical challenge worthy of deeper consideration. But first, allow me to underscore my surprise at the audience's reaction to the photograph and description of the skull medicine. Had I known that this description - and especially the photograph — would occasion such consternation, I would have selected an alternative illustration for my argument. My grounds for doing so, however, would have been rhetorical efficacy rather than ethical correctness; nevertheless, it is my interest in the latter that fuels the discussion that follows. 


\section{Religious Sensibilities}

With respect to publicizing the sacred, the ethical challenge considered here fits into a long and contentious history of the intersection of academic inquiry and religious (or spiritual or sacred) sensibility. Indeed, it barely warrants mention that inquiry in university settings is typically secular in nature, skeptical of religious claims, and suspicious of the politics and ideologies associated with religious experience. Typically, proponents of academic inquiry routinely declare that no set of beliefs and convictions should be "off-limits" to skeptical interrogation, presumably including Indigenous religious sensitivities. The good that follows from such inquiry is said to include enhancement of self-awareness, recognition of assumptions, refinement of convictions, and so on. Community psychologists, many of whom are academics, presumably value such outcomes, particularly when these serve emancipatory commitments in the context of community engagement (e.g., in contesting regimes of patriarchy or heteronormativity associated with some religious traditions). This is not even to mention the good associated with nuanced, critical, and historicized understandings of the world in general that might run counter to specific religious commitments. In this sense, it seems fair to ask whether and how American Indian objections to circulating Wildschut's photographs differ from fundamentalist Muslim objections to depicting the prophet Muhammed. In the latter instance, most university-based faculty members would vigorously defend the reproduction and circulation of such depictions in the context of substantive scholarly analysis as an expression of academic freedom.

And yet, perhaps the religious convictions of oppressed communities do in fact differ in crucial ways. The religious autonomy of American Indians, for example, was violated so routinely and severely (e.g., jailing for ceremonial participation) that Congressional protection was necessary through the American Indian Religious Freedom Act of 1978. Surely, it is not the

province of academic outsiders - and especially community psychologists - to challenge these remnant traditions. In response, I introduce two nuanced distinctions. The first pertains to the insider-outsider standing that a given community psychologist maintains in relationship to an oppressed community. There is a sense, of course, in which all academics are "outsiders" beyond their own professional communities, but some community psychologists preserve and cultivate stakes in community life based on shared social identity, kinship ties, life experience, and longterm commitment that reflect "insider" status. Despite the twin dangers of reductionism and 
essentialism that arise here, one can imagine that such "insider" community psychologists could be justified in asserting positions or adopting stances on controversial matters that reflect their allegiances and investments beyond those of "outsider" collaborators, consultants, and facilitators. The second nuanced distinction pertains to the pragmatic-ethical contrast, in which an "outsider" community psychologist might worry about difficult dialogues with community partners that entail interrogation or critique owing to risks for ongoing collaboration. And yet, no matter how ill-advised this may be with respect to project progress, it is difficult to see how entering in to such dialogues could be construed as an ethical breach per se.

These generic complications of the ethical challenge may be supplemented by more concrete observations regarding the specific religious sensibilities in question. First, it warrants mention that I personally have never been involved in purchasing medicine bundles, selling them to museums, photographing them, or publicizing knowledge about them that is not already contained in openly available sources such as extant scholarly monographs. Indeed, in keeping with “insider" status, I cannot even conceive of doing so, and feel thoroughly bound by community codes of respect and deference that flatly proscribe such activities. I will quickly note, however, that descriptive knowledge of the Braided Tail skull medicine has already been revealed - by Crow people, not by me - and remains permanently available to anyone with a library card or an internet connection. At the same time, the practical knowledge for ritually accessing power through this bundle disappeared a century ago (offering a new twist on the term disempowerment). It is in this sense historical knowledge (albeit with implications for illuminating traditional Indigenous understandings that remain relevant today), which explains why very few American Indians — and probably very few Crow tribal members - are familiar with the skull medicine traditions. In sum, this historical knowledge is available to anyone who wishes to find it, but remains relatively unknown to the descendants of those who once relied on such traditions for negotiating life's hardships. The striking paradox is that more community outsiders may in fact be familiar with this historical knowledge than community insiders.

\section{Postcolonial Critique}

With respect to postcolonial political critique, the ethical challenge considered here is complicated by the very historicity of some IKTs as just described. In fact, it was the loss of sacred ritual knowledge - reflecting the unwillingness or inability to transfer such knowledge during the early reservation era - that created an intergenerational predicament for many 
Indigenous communities on the northern Plains. A pressing question for many of our ancestors from that era was what to do with their sacred objects (and attending knowledge) in the face of sweeping transitions in community life that displaced or disrupted the continuity and relevance of many of these traditions. This was the context in which Wildschut collected Crow medicine bundles, suggesting an alternative interpretation to the Culture Vulture account described earlier. In contrast, this alternative interpretation might run as follows. During a truly desperate time for the Crow people, an area businessman found inspiration in Crow religious traditions. For nearly a decade of his life, and with adequate time, money, and connections, he sought to preserve sacred knowledge about medicine bundles that Crow people themselves acknowledged was quickly fading with the deaths of the "old timers." In the face of desperate poverty, an established tradition of transferring medicine power to interested parties for remuneration, an awareness that esoteric knowledge for accessing power through these bundles had passed along with their deceased owners, and an appreciation for a sympathetic White outsider who sought to document remnant knowledge for future generations, community members elected to part with these enigmatic heirlooms.

I refer to this latter account as the Black Elk Speaks version of the accession of the Braided Tail skull medicine, with reference to Nicholas Black Elk (Hehaka Sapa, 1863-1950). Black Elk, a Lakota holy man, famously "spoke" to writer John Neihardt (2014) about his seminal religious experience, a grand vision that he received during a period of illness in his youth. His decision in 1930 to share sacred knowledge with an interested White stranger in the context of spiritual disorientation and cultural discontinuity can be seen to parallel Wildschut's procurement of knowledge about Crow medicine bundles. The implications of the Black Elk Speaks account are radically different from those of the earlier Culture Vulture interpretation, emphasizing the exercise of Crow agency in response to an existential predicament rather than the exploitation of Crow vulnerability by an unscrupulous outsider. There is much of value at stake in this interpretive difference, for if we are to take Wildschut's (1960) monograph as a nefarious instance of contaminated knowledge, then we are consigning all that we know about some of these traditions - many of them described by actual Crow people to Wildschut in the twilight of such ritual practice - to the waste heap. Alternatively, for the Black Elk Speaks account of its provenance, it would not be our captivation by this Indigenous "way of knowing" that would raise concern but rather our indifference to this knowledge that would paradoxically 
repudiate a gift passed down from a prior generation of Crow people for all the world to value and appreciate. It remains an open historical question as to which of these interpretations better describes Wilschut's procurement of the Braided Tail skull medicine, although it is difficult to imagine how he could have assembled such detailed accounts of these medicine bundles through "grave robbery" or any other means that would have precluded close consultation with Crow people.

For my part, I find inspiration from my own ancestors, who resolved the predicament of discontinuity in sacred tradition rather decisively in favor of preservation through publicization. My great-great grandfather, The Boy (1872-1956), was the last member of our community to retain the ritual knowledge required for ceremonially opening our sacred Flat Pipe bundle. He conducted an abbreviated form of the ceremony on three occasions during the mid-twentieth century $(1938,1946$, and 1951), inviting White outsiders to attend-and photographs to be taken - on some of these occasions. More significantly, he led the effort beginning in the late 1930s to document the knowledge of pre-reservation Gros Ventre life-including our most sacred religious traditions - by collaborating closely with anthropologists in "this recording of our past way of living." As he explained during one of these consultations in 1941: "You will read it all when [Dr. John Cooper] writes it down all together... This man is going to put this record in several places to keep for all time" (cited, as translated, in Hartmann, 1984, p. 84). In addition, my great grandfather Frederick Peter Gone (1886-1967, no relation to The Boy) was employed as a reservation "field worker" through the Montana Writers Project in 1941-42 to preserve traditional knowledge for a proposed book on Montana's tribal communities. During this time, he authored 700 pages in longhand script dedicated to "History" and "Legends" of the Gros Ventre people. His seminal contribution was a biography of our most famous medicine man, Bull Lodge (ca. 1802-1886; see F. P. Gone, 1980). His purpose for writing the biography was unambiguous: "In order to explain what those supernatural powers were and how they worked, it was necessary that the life story of Bull Lodge be obtained" (Gone, 2006, p. 74).

Clearly, Indigenous community sensitivities about publicizing sacred knowledge have shifted over the decades. One key driver of this shift was the rise of the Red Power movement, a period of American Indian "ethnic renewal" that emerged late in the Civil Rights era in the USA (Nagel, 1995). Reclamation of Indigenous traditional spiritual practices featured prominently in this movement, such that today it is commonplace for American Indians to participate in sweat 
lodges, sun dances, and pipe ceremonies across Indian Country. This revitalization of sacred traditions has heralded a return to community proscriptions against publicizing ceremonial knowledge, but the very renewal of these practices has benefited from the (usually unacknowledged) consultation of the extant documentary record about such practices that was created by individuals such as Cooper, Hallowell, Neihardt, and Wildschut. In the end, there remains something disquieting about American Indian community objections to American Indian scholars who draw on this extant historical record insofar as this seems to suggest that only sympathetic White outsiders are ever considered legitimate academic conveyors of sacred Indigenous knowledge for a wider public audience (for recent examples, see Mohatt and Eagle Elk, 2000; Young, Rogers, \& Willier, 2015). This paradox did not go unnoticed by one of the foremost American Indian intellectuals of our age, the late Vine Deloria, Jr. (1933-2005). Specifically, Deloria recounted how his scholarly interests culminated in a request to participate in a kiva ceremony during a visit to one of the Pueblo villages. This was met with flat refusal by his hosts on the grounds of tribal secrecy and protection of sacred knowledge. Deloria, a strong advocate of Indigenous religious traditions, replied with no small hint of irony that he could accept this decision provided that he would not soon be reading all about these sacred practices in some forthcoming publication by an exuberant White anthropologist (S. R. Lyons, personal communication, November 11, 2016).

\section{Resolving the Ethical Challenge?}

The controversy occasioned by my academic presentation of the skull medicine tradition to a predominantly American Indian audience began to unfold during the remainder of the conference. One international Indigenous conference participant waylaid me during the lunch break to publicly and angrily berate me for recklessly "setting back" the tireless effort to legitimate IRMs. During this heated exchange, I simply observed that my contribution to the discussion had consisted of critical questions more so than established conclusions, that the future legitimacy of IRMs likely depended on our ability to address such questions in a thoughtful and sophisticated manner, and that the free expression of considered ideas harbored no threat to progress but rather would enhance the quest for legitimacy. Following lunch, one of the conference organizers privately inquired (with an edge in her voice) as to what it "felt like" to have offered remarks that had so angered and alienated the American Indians in attendance, even while appealing to the much smaller number of White participants in the conference. I 
replied that, in my view, such exchanges are not about feelings but rather about ideas, and that ideas deserve to be considered on their own merits with some degree of independence from the social identities of those who engage them. Most significantly, in the wake of the event, a graduate student organization associated with the conference invited me to engage in a "nonadversarial" collaboration with them as they prepared a "critical response" to my remarks. For three months, we exchanged email messages, scheduled phone meetings, and aired divergent perspectives about IRMs. In the end, in reaction to some of the arguments I have offered in this article, our collaboration collapsed, with the question of ethics surrounding my presentation of the skull medicine featuring prominently in this untidy outcome.

Thus, throughout this controversy, I have consistently advocated for the importance of ideas as fundamental to the cultivation, promotion, and legitimacy of emancipatory projects, with a clear emphasis on the caliber and quality of our most reasoned and seasoned understandings. Indeed, the reflections I offer in this article should be viewed as an expression of this commitment in response to the issues at hand, ones that I intend to share with parties to the controversy. The question remains, however, as to the nature of the relationship between rigorous thinking and critical analysis on the one hand and the stated values of community psychology on the other hand. The values that are said to shape community psychology have been recognizable at least since Rappaport (1977), continuing through to Vidal (2017): community, collaboration, diversity, empowerment, and prevention (among others). Considering such soaring aspirations, an emphasis on ideas can seem a paltry throwback to academic business as usual, a tired and distracting endorsement of the wrong side of familiar binaries such as thought versus action, aloofness versus engagement, or acquiescence versus resistance. And yet, despite the clear tensions that inhere between these concepts, I reject such simplistic oppositions to assert instead that ideas - when thoroughly considered and critically vetted - provide the most stable and enduring platforms for action, engagement, resistance, and so on.

The description, elucidation, and complication of the specific ethical challenge that I have offered in this article thus stands in for much broader ethical tensions or trade-offs that community psychologists confront in everyday scholarship and practice. The competing goods at stake are, on one hand, engagement of community constituencies in critical reflection and intellectual deliberation in ways that might challenge received orthodoxies and understandings and, on the other hand, encouragement, support, and facilitation of action by community partners 
in their own manner and on their own terms. Both can be seen to serve the emancipatory goals shared by most community psychologists, but my suspicion is that most community psychologists would enter only very reluctantly into a critical challenge of reigning community perspectives. As I have already noted, the dynamics of trading off these competing goods are refracted through the insider-outside status of community psychologists relative to their community collaborators, but these also likely depend on the duration, trust, and record of achievements associated with these partner relationships. I suspect that it will remain both an underexplored and contested ethical domain within the field as to the relative value of and appropriate conditions for academic attempts to unsettle received knowledge by community stakeholders in the promotion of community research and action.

Either way, it remains entirely plausible that some such efforts will get "sticky," or even "stuck." The ethical challenge associated with publicizing Indigenous sacred knowledge from published historical sources for scholarly purposes would appear to resist resolution in terms that would be acceptable to all relevant stakeholders. And yet, there are grounds for optimism, whether addressed to the tensions between American Indian religious sensibilities and academic knowledge, or to the broader question of the place of IKTs in university-based knowledge production, particularly within the realm of community research and action. Such optimism is fueled by the commitment of community psychologists to collaboration, which is reflected in the more recent examples of the publicization of sacred knowledge that I cited earlier. For example, Gerald Mohatt's partnership with Joseph Eagle Elk (2000) was based on long-term relations of mutuality and trust that ensured that Eagle Elk's voice predominates in their published account (with Mohatt serving principally in a curatorial role; for more detail, see Gone, 2016). Moreover, American Indian people themselves have entered academia as researchers and scholars in unprecedented numbers of late, kindling the kinds of intellectual exchanges and breakthroughs that will very likely refine ideas and understandings of both fellow academics and fellow Indigenous community members over time. All this bodes well for academic inquiry and community engagement in postcolonial Native America early in this new millennium.

\section{References}


Campbell, R. (2016). "It's the way that you do it": Developing an ethical framework for community psychology research and action. American Journal of Community Psychology. Advance online publication. doi:10.1002/ajcp.12037

Gone, F. P. (1980). The seven visions of Bull Lodge, as told to his daughter, Garter Snake (G. Horse Capture, Ed.). Lincoln, NE: University of Nebraska.

Gone, J. P. (2006). "As if reviewing his life": Bull Lodge's narrative and the mediation of selfrepresentation. American Indian Culture and Research Journal, 30(1), 67-86.

Gone, J. P. (2007). "We never was happy living like a Whiteman”: Mental health disparities and the postcolonial predicament in American Indian communities. American Journal of Community Psychology, 40(3-4), 290-300. doi:10.1007/s10464-007-9136-X

Gone, J. P. (2010). Psychotherapy and traditional healing for American Indians: Exploring the prospects for therapeutic integration. The Counseling Psychologist, 38(2), 166-235. doi:10.1177/0011000008330831

Gone, J. P. (2016). Alternative knowledges and the future of community psychology: Provocations from an American Indian healing tradition. Advance online publication. American Journal of Community Psychology. doi:10.1002/ajcp.12046

Gone, J. P., \& Calf Looking, P. E. (2015). The Blackfeet Indian culture camp: Auditioning an alternative indigenous treatment for substance use disorders. Psychological Services, 12(2), 83-91. doi:10.1037/ser0000013

Hallowell, A. I. (1976). Contributions to anthropology: Selected papers of A. Irving Hallowell. Chicago: University of Chicago.

Hartmann, M. C. (1984). As it was: History of Mission High School (Vol. 1). Chinook, MT: The Chinook Opinion.

Mason, J. A. (1961). [Review of the book Crow Indian medicine bundles, by W. Wildschut]. American Anthropologist, 63, 627-628.

Mohatt, G. \& Eagle Elk, J. (2000). The price of a gift. Lincoln, NE: University of Nebraska Press.

Nagel, J. (1995). American Indian ethnic renewal: Politics and the resurgence of identity. American Sociological Review, 60, 947-965.

Neihardt, J. G. (2014). Black Elk speaks: The complete edition. Lincoln, NE: University of Nebraska Press.

This article is protected by copyright. All rights reserved 
Rappaport, J. (1977). Community psychology: Values, research, and action. Fort Worth, TX: Holt, Rinehart, and Winston.

Vidal, A. S. (2017). The ethics of community psychology: Actors, values, options, and consequences. In M. A. Bond, I. Serrano-Garcia, \& C. B. Keys (Eds.), APA handbook of community psychology: Vol. 1. Theoretical foundations, core concepts, and emerging challenges (pp. 67-83). Washington, DC: American Psychological Association.

Wildschut, W. (1960). Crow Indian medicine bundles. New York: Museum of the American Indian, Heye Foundation.

Young, D., Rogers, R., \& Willier, R. (2015). A Cree healer and his medicine bundle: Revelations of Indigenous wisdom-Healing plants, practices, and stories. Berkeley, CA: North Atlantic Books.

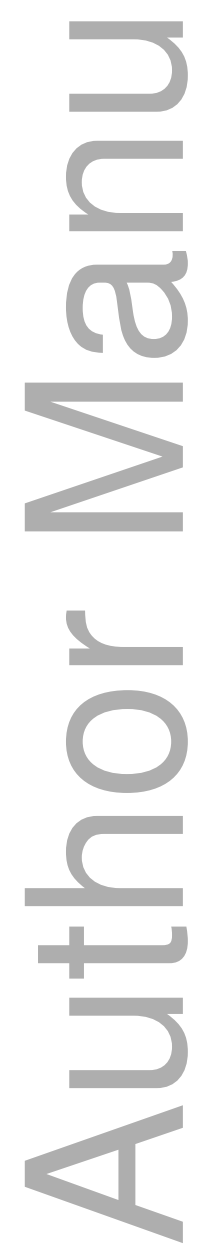

This article is protected by copyright. All rights reserved 